\title{
This is my unit: Chris Hani Baragwanath ICU, Soweto, South Africa
}

Stephilia Tshukutsoane, CCRN, B Cur (Hon), ICU Research Coordinator, Baragwanath Hospital, Soweto, South Africa. Juan Scribante, CCRN, M Cur, Research Manager, Department of Anaesthesiology, University of the Witwatersrand, Johannesburg, South Africa.

E-mail: stephiliat@yahoo.com

Key Words: critical care intensive care unit nursing * South Africa * Soweto

\section{SUMMARY}

- This article provides a brief history of Chris Hani Baragwanath Hospital and our intensive care unit.

- It describes the functioning of our unit today and some of the challenges we are confronted with.

CHRIS HANI BARAGWANATH HOSPITAL: YESTERDAY AND TODAY

Shortly after the start of the Second World War in 1939, Britain decided to build two hospitals in South Africa to care for military personnel, one of which was the Chris Hani Baragwanath Hospital. The British Government paid $£ 328,000$ for a 1544 bed hospital to be built in Soweto, a few kilometres outside Johannesburg. The hospital was developed nearby a then well known refreshment post called "Baragwanath Place" run by a Cornish gentleman John Albert Baragwanath in the late 1800s. After various experiments with names it was decided to call the hospital "The Imperial Military Hospital, Baragwanath".

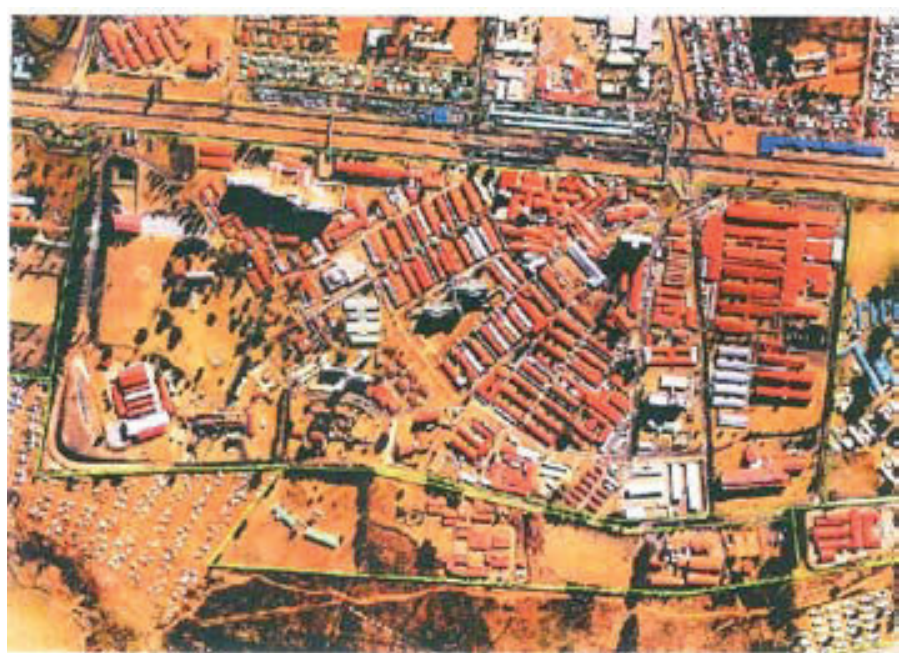

Photograph 1. Aerial view of the hospital

Field Marshall Jan Smuts officially opened the hospital on the 23rd September 1942. Initially war casualties mainly from the Middle East Command were treated here, but during the latter part of the war, the hospital treated mostly tuberculosis patients from the Far and Middle East. During the Royal visit in 1947, King George used the opportunity to present medals to the British and Commonwealth troops that were still recovering here.

After the war the South African Government bought the hospital for one million pounds with the intention to use it for the black population of the greater Johannesburg area. The first patients were transferred here on 1 April 1948

Over the next few decades the hospital expanded in size and status. Today it serves the Soweto community of officially one million, unofficially reported as 3,5 million people and is a referral hospital for a large part of the country and surrounding African States. In 1994 the now 3000-bed Baragwanath Hospital was listed in the Guinness book of records as the largest hospital in the world. The hospital gained international status for its training of health personnel (many became international leaders in their field) and research that was undertaken here over the years.

After the tragic murder of a prominent South African activist Chris Hani, the hospital was renamed in 1997 as the "Chris Hani Baragwanath Hospital". Today, due to monetary and manpower resource constraints only 2500 beds are operational.

\section{THE UNIT: YESTERDAY}

The ICU was established in the early seventies to cater for the increasing number of critically ill patients that were nursed in different wards of the hospital by special teams of nurses. As the hospital was built as a typical single storey war hospital long before the development of ICUs, the result is that our unit is not centrally located in the hospital. The unit is in a double storey building with two identical floors located next to the theatre complex, approximately $500 \mathrm{~m}$ from the emergency department.

The unit was officially opened on the 2nd February 1975 and at the time was regarded as the largest and most modern in the southern hemisphere.

Each floor comprises of an open area with 12 beds and six beds in glass cubicles for a total of 18 beds. When the unit first opened only four beds were functional. The medical director obtained ICU experience in the United States and was at the time the only doctor in the unit with ICU experience. The first nurses working in the unit were also not formally ICU trained. A year after the opening of the unit, both floors with a total of 36 beds were fully functional. Since inception the unit has been a closed multi-disciplinary ICU.

\section{THE UNIT: TODAY}

Nursing personnel

A nursing unit manager and her deputy manage our unit. A clinical 
instructor is responsible for orientation of newly appointed staff and accompanying of critical care nursing students. The research coordinator coordinates all research in the unit, although currently only medical research is undertaken.

There are 90 nurses allocated to direct patient care, of which 64 are ICU trained. South Africa is currently experiencing a severe nursing shortage and the national average is 1.1 nurses per ICU/high care bed. Although our unit is also hamstrung by this shortage, we fare better than most other units with a ratio of 3.5 nurses.

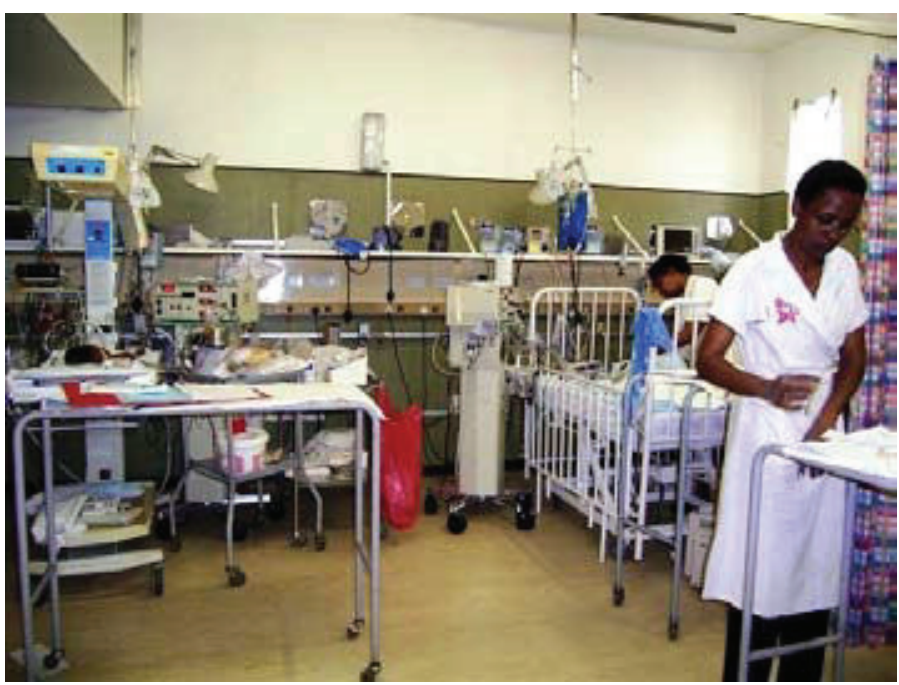

Photograph 2. Inside the intensive care unit

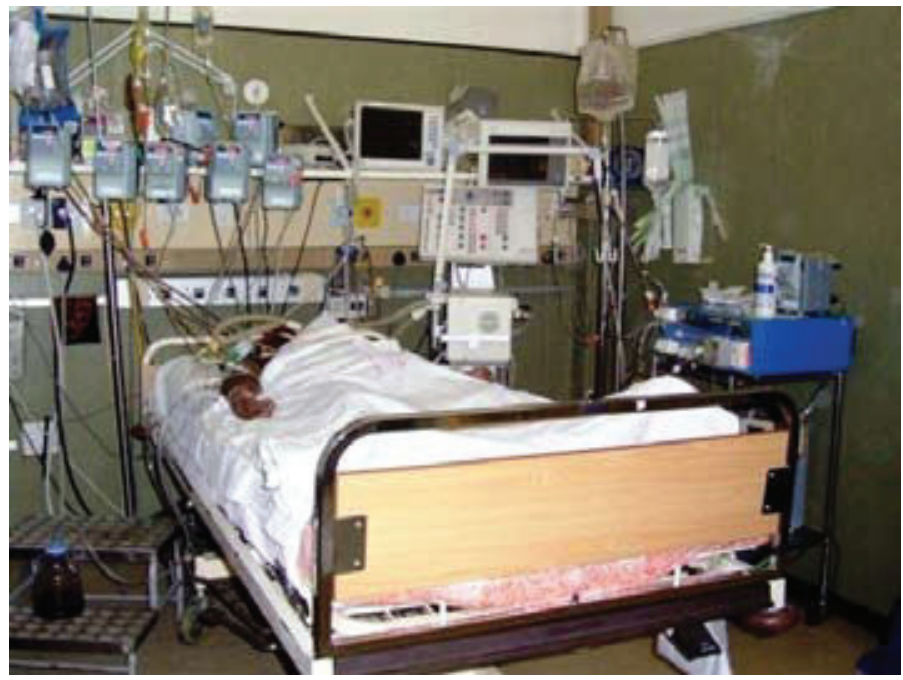

Photograph 3. A typical ICU patient

To ensure continuity of nursing care, our nurses are equally divided into four groups. Each group has a shift leader and a deputy who must also be ICU trained. The shift leader is not allocated a patient but is responsible for the overall supervision of patient care. Nurses are allowed to select which patient they will be assigned for the specific week, but the shift leader can reassess the patient allocation as the situation in the unit changes. Day shift is from 07:00 to 19:00 and night shift from 19:00 to 07:00. The nursing staff rotates weekly between adult and paediatric patients and work a total of 160 hours per month. Newly employed staff members are orientated for one month before being first allocated to a patient. A mentor is appointed to new staff members and they have the opportunity to work in each of the four groups before being permanently assigned to a specific group.

A monthly in-service lecture is held for nurses on a topic of their choice and nurses are free to join the daily multi-disciplinary teaching round. Once a week there is a special round where interesting cases are presented and staff from other departments and hospitals joins the round. The Critical Care Society of Southern Africa annually hosts a national congress and a separate refresher course and six nurses are sponsored to each of these events. Every year four to six nurses are enrolled to do a year long critical care nursing postgraduate diploma.

\section{Medical personnel}

The medical staff complement consists of a medical director and eight specialist physicians (anaesthesiologists, chemical pathologists, paediatricians, and pulmonologists). Of these specialists, five have an additional qualification as intensivists. Registrars from different disciplines rotate through the unit as part of their specialisation programme. The unit has 24 hour on site medical cover and is accredited as an intensivist training facility.

\section{Patient profile and management}

Today we have $18 \mathrm{ICU}$ beds functional on the first floor and the second floor has been turned into a high dependency unit with eight beds. These changes have been mainly due to personnel constraints. During 2006 the ICU section admitted 632 patients with an average bed occupancy of $95 \%$. Some $86 \%$ of admissions were emergency admissions and $37 \%$ of the adult patients were trauma patients. The average ICU stay is nine days.

All ICU patients, with the exception of burns, non-ventilated coronary care, neuro-surgery and neonates born in our hospital, are admitted to our unit. Neonates transferred from other hospitals are admitted to our unit.

The community served by the hospital is mostly poor. Illiteracy prevails and traditional medicine still plays an important role. We therefore commonly find patients presenting late in their disease process to hospital, which has a significant influence on patient mortality, morbidity rate and length of ICU stay. ICU admission triage is a huge challenge for the medical consultant on call and the principle of distributive justice is used to determine if a patient should be admitted to our unit.

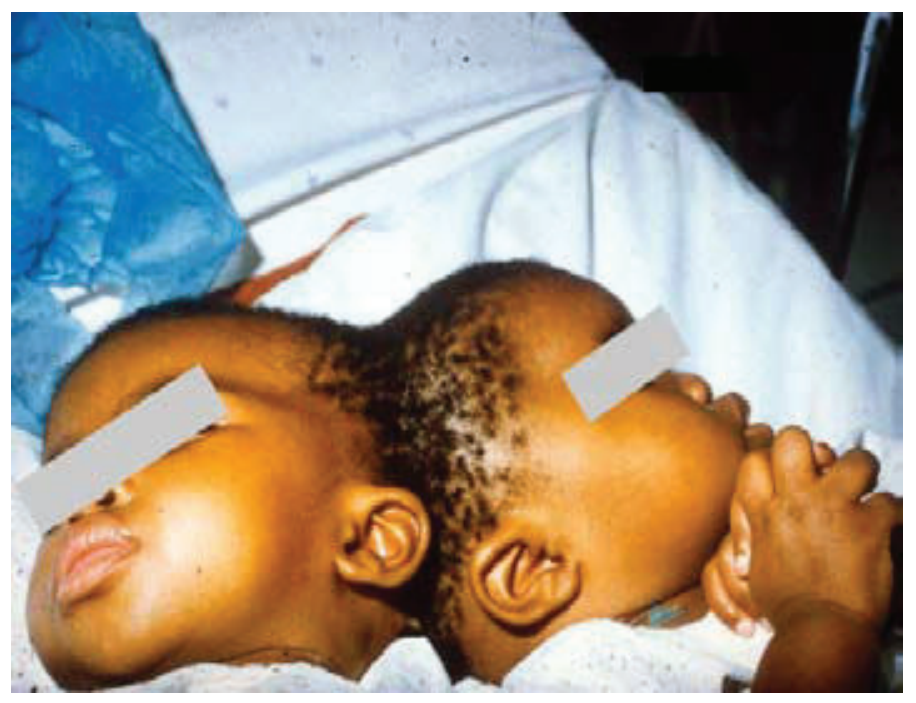

Photograph 4. One of the Siamese twins developed a bradycardia pre-separation and received intravenous atropine. The other twin then developed a tachycardia that had to be treated.

Patients with many interesting and rare pathologies are treated in our unit for example the separation of several Siamese twins (see photograph 4). Often we are confronted with the dichotomy of first world medicine and third world values. In photograph 5, a sangoma (a traditional healer) is visiting his wife, a patient in the unit, and she is enrolled in a selective digestive tract decontamination research study. 


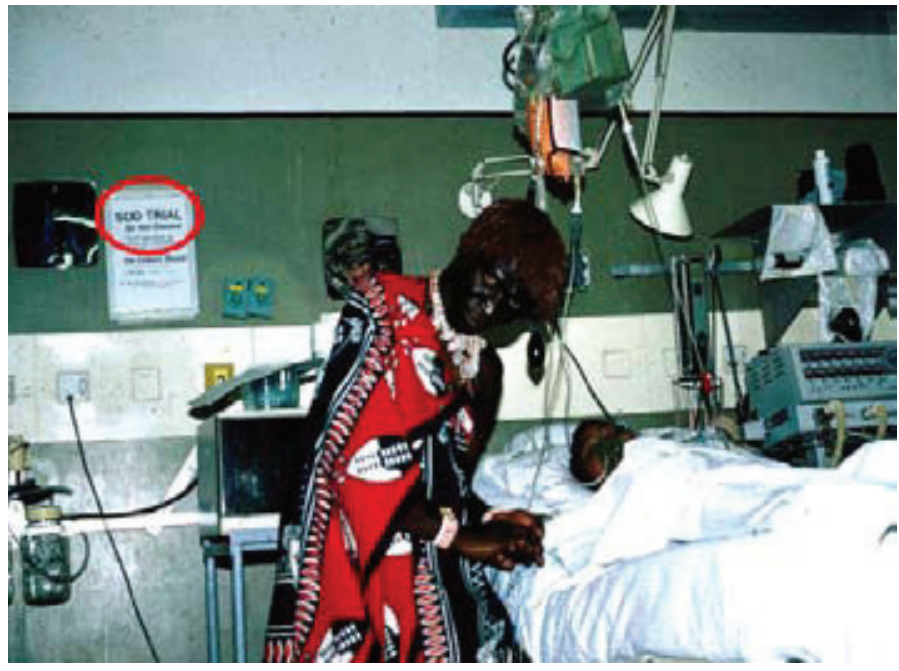

Photograph 5. A sangoma (traditional healer) visits his wife in ICU

The unit is equipped with state of the art equipment. A variety of ventilation modes are used including high frequency oscillation ventilation. A technician is available during office hours to provide first line equipment support and limited laboratory assistance. We do not have the luxury of phlebotomists, respiratory technicians or a renal replacement therapy team and all these functions are undertaken by nurses rendering direct nursing care. Physiotherapists are consulted as and when the need arises.

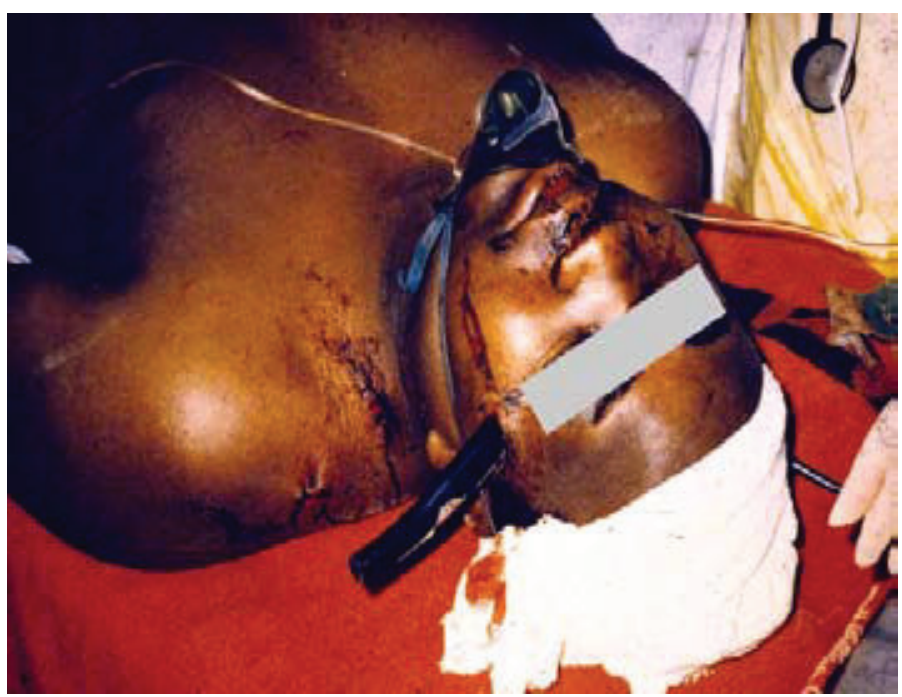

Photograph 6. This patient was admitted with a knife sticking right through his skull. The knife was removed and the patient was discharged a few days later, reportedly 'normal'.

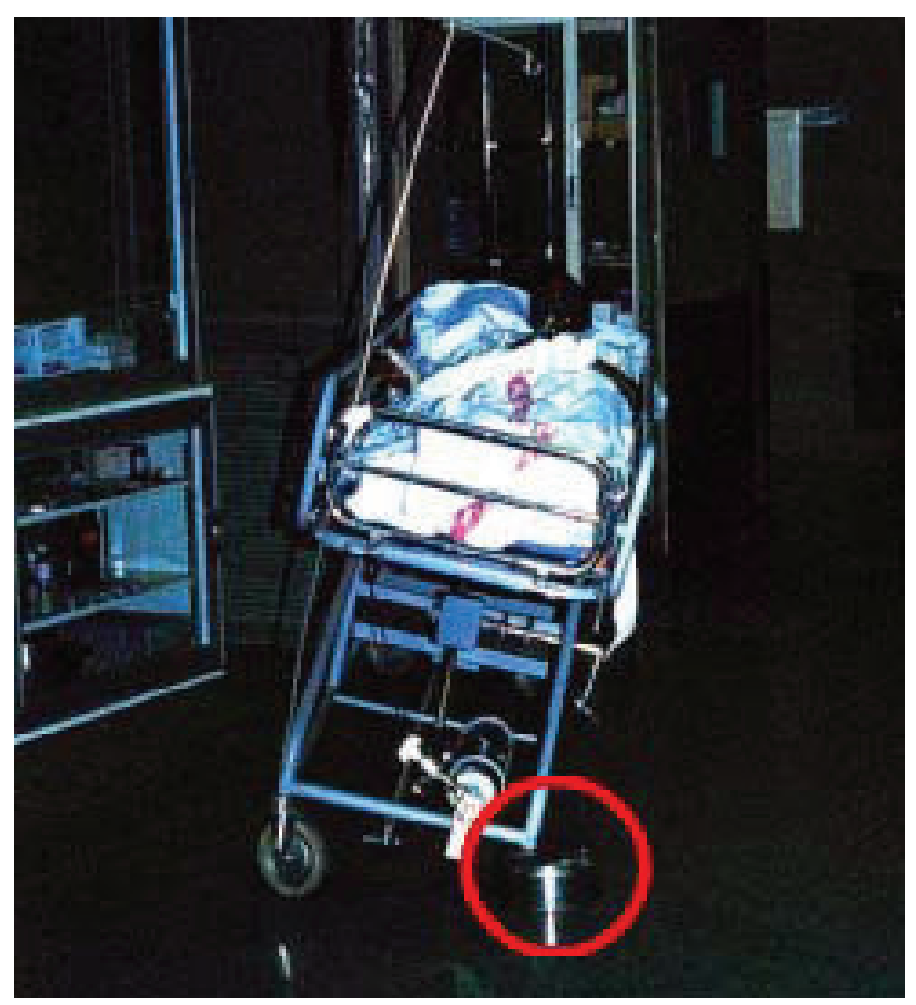

Photograph 7. Not only is it a headache to admit a patient to the unit but also sometimes it is a headache to discharge a patient. This patient is ready for discharge, but the trolley only has three wheels!

\section{CONCLUSION}

Professor Jeff Lipman, a previous medical director, referred to working in our unit as a "headache" - it is a headache to get a patient admitted to the unit, there are never enough beds and once admitted to the unit the patients cause their fair share of headaches for the staff (see photographs 6 and 7). Nevertheless, it is always a challenge to work in our unit and there is never a dull moment. Over the last three decades it has remained a unique unit where a special camaraderie prevails that has served our community well.

\section{REFERENCE}

http://www.chrishanibaragwanathhospital.co.za 